\title{
Influence of the scheme of air exchange organization in the room on the efficiency of the air-jet hood of the heat treatment chamber
}

\author{
Tatyana Zhilkina1, Viktor Pukhkal', ${ }^{2}$, and Vladislav Pankov²
}

\begin{abstract}
${ }^{1}$ Moscow State University of Civil Engineering, 129337, 26, Yaroslavskoe Shosse, Moscow, Russia ${ }^{2}$ Saint Petersburg State University of Architecture and Civil Engineering, 4 Vtoraya Krasnoarmeiskaya, 190005, Saint Petersburg, Russia
\end{abstract}

\begin{abstract}
Local exhaust ventilation allows maximizing the localization of hazards with minimum values of air exchange in the room. For the study, the design of a local exhaust in the form of an air-jet hood at an open doorway of the UKM Classic M 2005 chamber by Mauting was adopted. Geometric models have been developed, including a heat treatment chamber, a room from which the chamber is loaded, a supply and exhaust hood over the door from the chamber to the room, and a supply air duct with air distributing devices. The results of a computational experiment on modeling the operation of the local exhaust ventilation system of the heat treatment chamber are presented. The STAR-CCM+ software package was used as a calculation program. The calculation results were analyzed. The influence of the air exchange scheme (location of the supply devices) in the room on the efficiency of the local exhaust devices (supply and exhaust hood) has been established.
\end{abstract}

\section{Introduction}

The organization of air exchange is understood as the relative position of the places for supply and removal of ventilation air in the room, depending on the location of sources of harmful emissions and workplaces [1]. In works [2,3], the characteristics of local exhaust devices are considered in order to optimize air exchange. It is shown that the efficiency of trapping harmful emissions depends on the design, aerodynamic and operating parameters of local exhaust devices.

When determining the characteristics of local exhaust devices, the influence of the air supply scheme is not taken into account [1-6]. Therefore, the purpose of this study is to assess the influence of the scheme of air supply into the room on the efficiency of local exhaust devices.

For the study, open-type exhaust units were adopted - hoods located outside the source of harmful emissions, i.e. above or on the side of it, in particular, air-jet hoods (supply and exhaust hoods).

\footnotetext{
*Corresponding author: pva1111@ rambler.ru
} 
The work of the supply and exhaust hood (air-jet hood) at the doorway of the UKM Classic M 2005 chamber by Mauting [7], intended for heat treatment of meat products in the food industry, is considered. The supply and exhaust hood is built on the basis of the design of the KVF supply and exhaust hood by Halton [8-10].

In the design of the supply and exhaust hood of the KVF model, three air diffusers are located on the bottom of the front side of the hood, creating concentrated jets for supplying air from top to bottom in order to create an air curtain.

\section{Materials and methods}

For modeling, the characteristics of the UKM Classic M 2005 heat treatment chamber are taken [7]:

- doorway of the chamber with a width $a=1.87 \mathrm{~m}$, height $\mathrm{b}=2.30 \mathrm{~m}$;

- chamber length $5.3 \mathrm{~m}$;

- height of the hood attachment from the axis of the chamber doorway $-\mathrm{H}=1.15 \mathrm{~m}$.

- temperature of the gas-air mixture inside the chamber $-\operatorname{tg}=60{ }^{\circ} \mathrm{C}$;

- room temperature $-\operatorname{tr}=18^{\circ} \mathrm{C}$.

The section of the room, into which the chamber doorway opens, is a working area related to this heat treatment chamber. Site dimensions: height - $4.6 \mathrm{~m}$, length $-3.87 \mathrm{~m}$, width $-4 \mathrm{~m}$.

Geometric models have been developed (Figure 1), including: heat treatment chamber; the area of the room adjacent to the chamber, from which the chamber is loaded; a supply and exhaust hood above the door from the chamber to the room; supply air duct with air distributing devices.

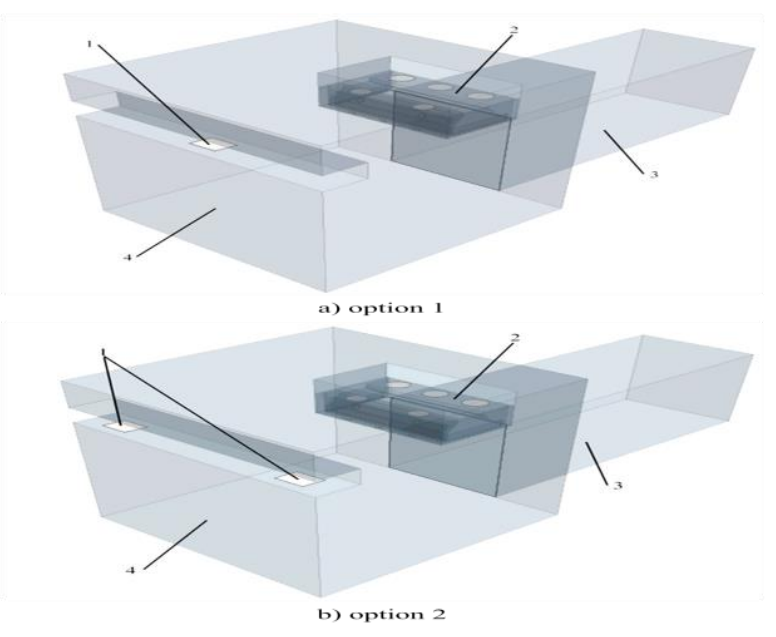

Fig. 1. Geometric models of the heat treatment chamber. 1 - supply openings; 2 - supply and exhaust hood (air-jet hood) 3 - heat treatment chamber; 4 - room.

Two versions of the heat treatment chamber models were created in the SolidWorks software (Figure 1):

- a model with a supply and exhaust hood over the chamber doorway and an inflow arranged in the center of the room (option 1); air inflow is made through an opening with dimensions of $400 \times 300 \mathrm{~mm}$ located at a height of $3.75 \mathrm{~m}$;

- a model with a supply and exhaust hood above the chamber doorway and an inflow organized into the side zones of the room (option 2); air inflow is made through two openings with dimensions of $400 \times 300 \mathrm{~mm}$ located at a height of $3.75 \mathrm{~m}$.

Exhaust through the hood is fully compensated by the supply. 
The STAR-CCM+ software package is used as a calculation program.

Modeling the process of operation of local exhaust ventilation from the heat treatment chamber is divided into 2 stages:

- the first stage - modeling the operation of supply and exhaust ventilation in the area of the room with the closed door to the heat treatment chamber, is carried out until the establishment of a stationary mode in the room; this stage is intermediate before the main one;

- the second stage (main) - modeling the work of local exhaust from the chamber doorway; begins after the end of the first stage, simultaneously with opening the door to the heat treatment chamber and combining the volumes of the room and the chamber, continues until the removal of heat and gas emissions escaping through the doorway of the chamber into the room.

The model has the following assumptions:

- on the surfaces of enclosing structures, heat treatment chamber, supply air duct and hood - adiabatic conditions;

- components with insignificant concentration are excluded from the gas composition of the chamber and the following mass fractions of the mixture components are taken: water vapor $1.01 \%$, dry air $98.79 \%$, carbon monoxide (CO) $0.01 \%$, carbon dioxide (CO2) $0.19 \%$;

- gas mixture - an ideal incompressible gas, the components of the mixture do not enter into chemical reactions.

In numerical modeling, the equations of motion (Navier-Stokes), the equation of continuity and the equation of heat transfer were used $[11,12]$. To take into account the turbulent nature of the motion of the medium, the k- $\varepsilon$-model of turbulence is used. The nonstationary implicit method of calculation is adopted.

The numerical experiment provides for the control of temperature and air velocity. At the second stage, after opening the door to the heat treatment chamber, the air velocity and the temperature of the gas-air mixture in the volume of the model are controlled. The control is carried out using real-time display of velocity and temperature fields in the characteristic sections of the model shown in Figure 2. The fields of velocities and temperatures in the required and sufficient volume display information that allows assessing the efficiency of the local exhaust device.

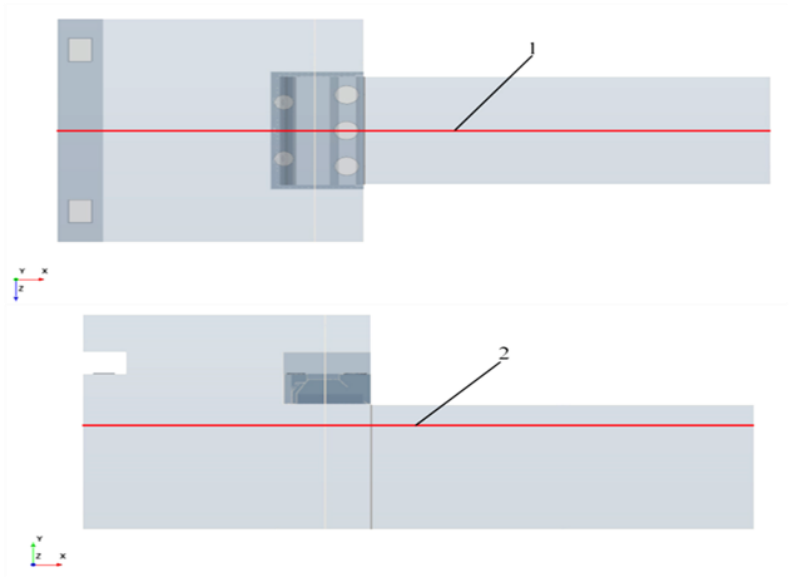

Fig. 2. Typical sections of the model. 1 - vertical section; 2 - horizontal section.

At the zero moment of time, a stationary air flow regime is established in the room in front of the heat treatment chamber. There are no disturbing influences inside the chamber, the door to the chamber is closed. 
Modeling the operation of the supply and exhaust hood begins from the moment the door to the heat treatment chamber is opened, and the volumes of the room and chamber are combined.

\section{Results}

To compare the options for supplying air to the room, pre-determined values of air flow rates were adopted in accordance with the recommendations [7,9]. Calculations were made for two exhaust air flow rates -3000 and $4500 \mathrm{~m} 3 / \mathrm{h}$. Below are the data of the most effective options: supply air flow rate into the room - $3780 \mathrm{~m} 3 / \mathrm{h}$; supply air flow rate in the supply and exhaust hood through the holes for concentrated supply - $720 \mathrm{~m} 3 / \mathrm{h}$; the flow rate of air removed through the hood structure $-4500 \mathrm{~m} 3 / \mathrm{h}$.

\subsection{Calculation results for option 1: with one air inlet located in the center of the serviced room}

After opening the chamber door, the gas-air mixture exits the heat treatment chamber through the open doorway in its upper zone. A leakage of the hot air of the chamber through the edge of the supply and exhaust hood is formed. The flow vector of the supply jets of the hood is displaced in the vertical plane towards the door of the heat treatment chamber. Starting from 20 seconds, the supply jets at the outlet of the hood deflect towards the room. The temperature of the gas-air mixture in the working area of the room does not exceed $30^{\circ} \mathrm{C}$.

Seventy five seconds after opening the chamber door, the spread of the gas-air mixture in the working area of the room reaches the maximum values shown in the experimental calculations. The overflow of the gas-air mixture of the chamber into the working area of the room is observed.

The calculation results 75 seconds after opening the door to the heat treatment chamber are shown in Figure 3.

When the inlet opening was located in the center of the room, the supply air jet was laid on the vertical wall, then on the floor, and the supply air entered the chamber, which facilitates the release of the gas-air mixture from the heat treatment chamber into the room volume. In the case of using a supply-and-exhaust hood, the above-described effect leads to intense ejection of the hot air flow of the chamber by the supply jets of the hood, and a significant spread of the gas-air mixture in the working area of the room.

\subsection{Calculation results for option 2: with two air inlets located at the edges of the serviced room}

Ten seconds after opening the chamber door, the air-gas mixture exits the heat treatment chamber through an open doorway in its upper zone. The supply jets of the supply and exhaust hood are deflected relative to the vertical axis towards the chamber doorway. The distribution of temperatures in the zone of replacement of the gas-air mixture of the chamber with supplied air indicates intensive mixing and heat and mass transfer processes.

In 20 seconds after opening the chamber door, a leakage of the gas-air mixture of the heat treatment chamber is observed through the supply cut-off jets at the edge of the supply and exhaust hood. However, at a given flow rate of the removed air, the volume and temperature of the gas-air mixture leaving the edge of the hood are insignificant. Partial ejection of hot air coming out of the heat treatment chamber by the inflow jets of the hood is noted, without transferring them to the working area of the room. 
Thirty seconds after opening the chamber door, the volume of hot air leaking through the edge of the hood increases. The maximum temperature of the hot gas-air mixture at the place of leakage reaches $35^{\circ} \mathrm{C}$. There is an insignificant removal of the volumes of the mixture of the supply air and the gas-air mixture of the chamber near the floor of the room due to the collision of the hood supply jets with it.

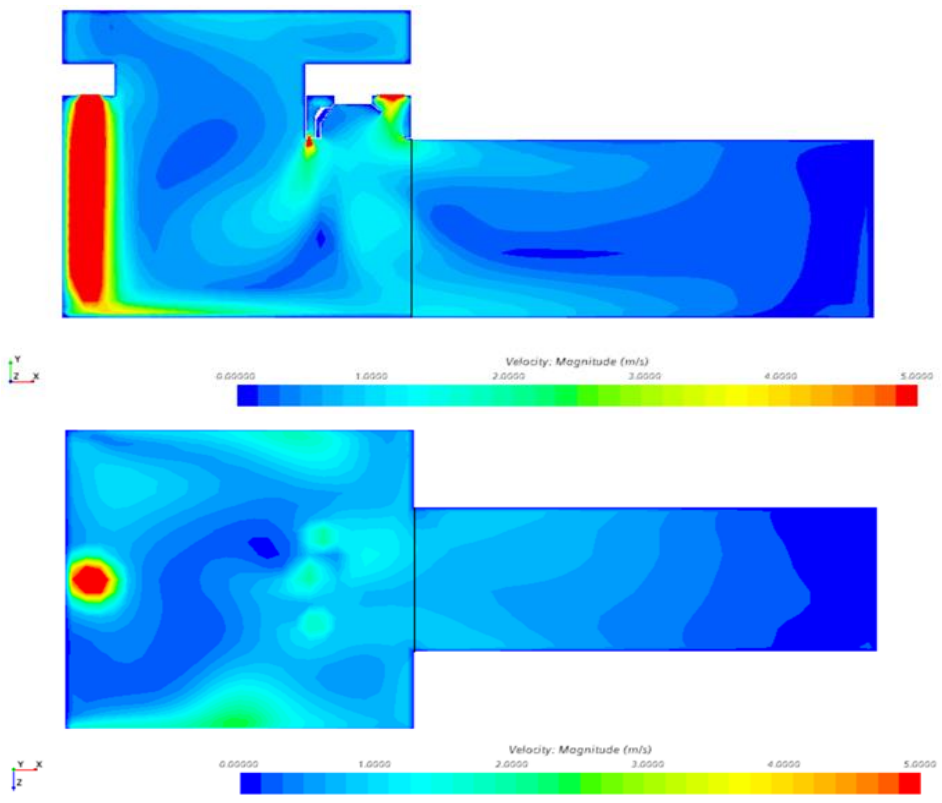

a) velocity fields
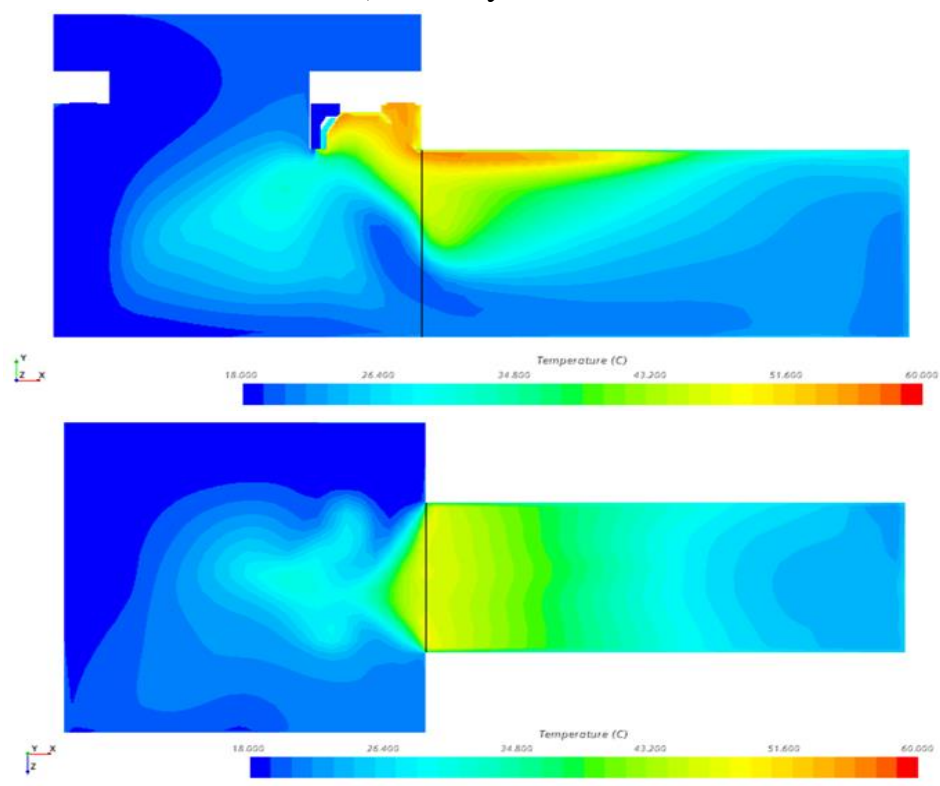

b) temperature fields

Fig. 3. Fields of velocities and temperatures in typical sections of the model 75 seconds after opening the door to the chamber (option 1). 
Fifty five seconds after opening the chamber door, a part of the gas-air mixture that has broken through the supply and exhaust hood spreads in the upper part of the room. Due to the dilution of the hot air in the room, the deviation of the gas temperature in the upper zone from the background values is insignificant. There is no active propagation of hot air leakage through the edge of the hood in the volume of the room. At the same time, an increase in the spread of the mixture of the supply air of the hood and the hot air of the chamber is observed in the lower part of the working area of the room.

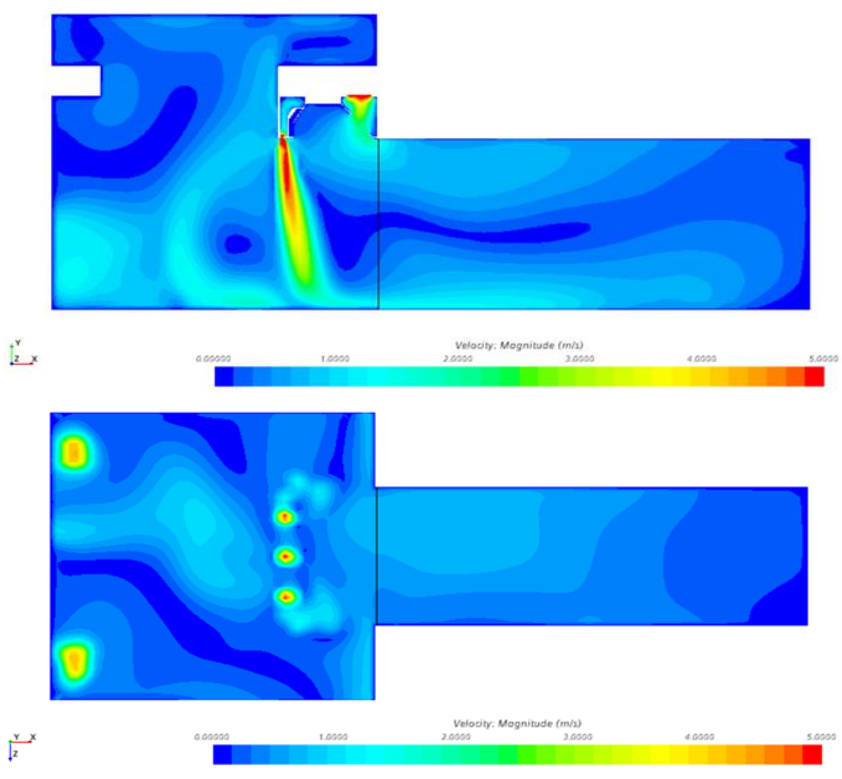

a) velocity fields

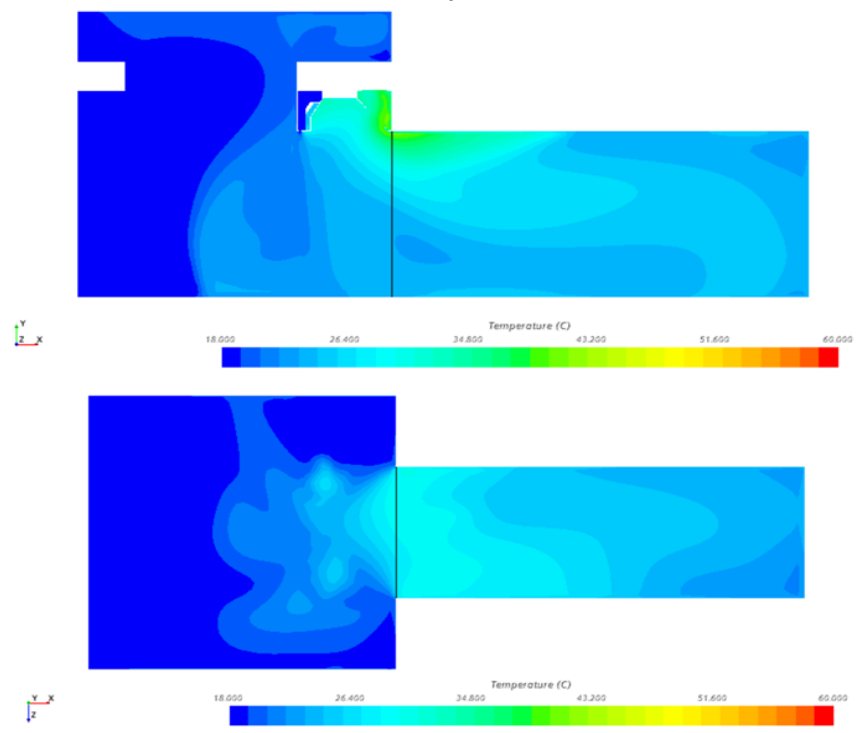

b) temperature fields

Fig. 4. Fields of velocities and temperatures in typical sections of the model 75 seconds after opening the door to the chamber (option 2). 
Removal of most of the volume of the gas-air mixture of the heat treatment chamber is completed 75 seconds after the chamber door is opened (Figure 4). The air temperature in the chamber volume exceeds $30^{\circ} \mathrm{C}$. No air leakage over the edge of the hood is observed. Part of the hot air that entered the room earlier is dispersed in the upper area of the room. The outlet of a mixture of the supply air of the hood and the hot air of the chamber, carried by the supply jets of the supply and exhaust hood, was widely dispersed. The temperature in the working area in front of the chamber doorway does not exceed $25^{\circ} \mathrm{C}$.

Seventy five seconds after opening the chamber door, the removal of most of the gas-air mixture in the heat treatment chamber was completed. However, due to active mixing of the supply air with the hot air of the chamber, the temperature in its volume exceeds $30^{\circ} \mathrm{C}$. A leakage through the edge of the hood is no longer observed, so part of the hot air that entered the room earlier is dispersed in the upper area of the room. The outlet of a mixture of the supply air of the hood and the hot air of the chamber, carried by the supply jets of the supply and exhaust hood, was widely dispersed. Due to the small volumes of heat and mass transfer and active dilution in the room air, the temperature in the working area in front of the chamber doorway does not exceed $25^{\circ} \mathrm{C}$.

The calculation results 75 seconds after opening the door of the heat treatment chamber are shown in Figure 4.

\section{Conclusion}

1. The influence of the air exchange organization scheme (location of air inlets) in a room on the efficiency of local exhaust devices (supply and exhaust hood) has been established.

2. Based on the results of calculations of the models of operation of the supply and exhaust hood with different organization of the inflow into the room, the following conclusions can be drawn:

- when air is supplied through two air inlets located at the edges of the room, the distribution of air flows in the model space has a fundamentally different character compared to the model with one air inlet in the center of the room. There is no deflection of the supply jets of the hood into the working area of the room, as well as there is no significant spread of the hot air ejected by them;

- when air is supplied through two inlet openings, at all design flow rates of the air removed by the supply and exhaust hood, a leakage of the gas-air mixture of the chamber through the edge of the hood is observed. At a flow rate of $4500 \mathrm{~m} 3 / \mathrm{h}$, the volume of hot air that entered the room as a result of a leakage is insignificant and is concentrated in the upper zone of the room;

- when air is supplied through one inlet opening, a mixture of hot air from the chamber, ejected by the supply jets of the hood, enters the working area of the room. The supply jet is laid on the floor of the room and enters the lower zone of the chamber, as a result of which the gas-air mixture is forced out of the chamber in the upper zone.

\section{References}

1. M.S. Kuzmin, P.A. Ovchinnikov, Exhaust and air distribution devices. Stroyizdat, Moscow (1987)

2. A.G. Sotnikov, A.G. Borovitsky, Systematization and generalization of the characteristics of local exhaust devices - the basis of the engineering methodology for the design of effective SV, Magazine of Civil Engineering 6(32), 54-59 (2012) doi: 10.5862/MCE.32.8. 
3. A.G. Sotnikov, A.A. Borovitsky, Theoretical and experimental substantiation of the method for optimizing air exchange in industrial ventilation systems, Magazine of Civil Engineering 28(2), 32-38 (2012) doi: 10.5862/MCE.28.5.

4. V.D. Stoler, Y.L. Saveliev, Y.A. Ivanov, V.L. Shegal, Effective devices of local ventilation at industrial facilities. Publishing house "Lan", SPb (2017)

5. A.B. Sulin, V.V. Stepanov, D.V. Neganov, A.A. Sedova, Calculation substantiation of the minimum required performance of the local exhaust ventilation system, Bulletin of civil engineers 6(47), 169-173 (2014)

6. I. Kulmala, P. Hynynen, I. Welling, A. Saamanen, Local ventilation Solution for Large, Warm Emission Sources, Annals of Occupational Hygiene 51(1), 35-43 (2007) doi: 10.1093/annhyg/mel049

7. MAUTING equipment technical catalog, https://docplayer.ru/7686978-Mautingclassic-mauting-classic.html, last accessed 2020/05/31.

8. Capture Jet ${ }^{\mathrm{TM}}$ Hood, https://www.halton.com/ru_RU/foodservice/products//product/KVF, last accessed 2020/05/31.

9. Capture Jet ${ }^{\mathrm{TM}}$ Hood with Supply Air and Side-Jet Technology, https://www.halton.com/dh/EAAS0yFGPNRGhAEilsGFd51CqZk35HAluEFFMsXf7M Nwnr7jlqjm0-VxOgA9_hD-qMi39ODS-

MiNMiKhdZ9iHWGiFKVfuzDA2XdisIWU0spLtatfIMaAgm-

N18VLSjMq/Halton_FS_KVF_Capture_Jet_Hoods_uk.pdf, last accessed 2020/05/31.

10. V. Pukhkal, V. Pankov, D. Spitsov, Air-jet cover for heat treatment chamber. IOP Publishing, Journal of Physics: Conference Series 1614, 012075 (2020) doi: 10.1088/1742-6596/1614/1/012075.

11. T.A. Datsyuk, A.V. Sauts, B.N. Yurmanov, V.R. Taurit, Modeling of ventilation processes, Modern problems of science and education 5, (2012)

12. I.N. Logachev, K.I. Logachev, O.A. Averkova, Local Exhaust Ventilation: Aerodynamic Processes and Calculations of Dust Emissions. Boca Raton: CRC Press (2015)

13. V Alpatov and M Balzannikov 2018 IOP Conf. Ser.: Mater. Sci. Eng. 456 012011. DOI: 10.1088/1757-899X/456/1/012011

14. Vadim Alpatov, Alexey Lukin, Irina Laguta MATEC Web Conf. 25104007 (2018). DOI: 10.1051/matecconf/201825104007

15. A. O. Lukin and V. Y. Alpatov, "Influence of a Metal Beam of a Corrugated Wall Geometrical Parameters on Size and Nature of Internal Tension Distribution", Materials Science Forum, Vol. 931, pp. 247-251, 2018. DOI: https://doi.org/10.4028/www.scientific.net/MSF.931.247

16. Vladimir Zubkov, Alexey Lukin, Vadim Alpatov MATEC Web Conf. 19601005 (2018). DOI: 10.1051/matecconf/201819601005

17. Vadim Alpatov, Alexey Soloviev MATEC Web Conf. 19601008 (2018). DOI: 10.1051/matecconf/201819601008

18. Vadim Alpatov and Andrey Sakharov IOP Conf. Series: Materials Science and Engineering 365 (2018) 062022 doi:10.1088/1757-899X/365/6/062022

19. Dmitry Chernyshev, Vadim Alpatov MATEC Web Conf. 11700028 (2017). DOI: 10.1051/matecconf/201711700028 